\title{
ASPECTOS LOGÍSTICOS E INSTITUCIONAIS QUE AFETAM A OFERTA DA SOJA LIVRE DE TRANSGÊNICOS
}

\author{
Fabrício Oliveira Leitão* \\ Sérgio Ronaldo Graneman** \\ Adelaida Pallavicini Fonseca*** \\ Warley Henrique da Silva****
}

RESUMO: Este trabalho buscou identificar as mudanças ocorridas na Cadeia Logística da Soja bem como os impactos aos elos que a compõem (produtores, armazenadores/processadores, transportadores rodoviários, operadores ferroviários e portuários), em decorrência do advento e da difusão da soja transgênica, sob uma ótica sistêmica dos problemas que envolvem sua segregação. Para isso, foram identificados os pontos críticos e os cuidados e procedimentos necessários para a não contaminação da soja ao longo da Cadeia, garantindo assim a pureza do produto e o recebimento do prêmio pela segregação. O estudo foi de natureza exploratória, com abordagem qualitativa. Os resultados permitiram concluir que o elo armazenador/ processador assume papel fundamental na coordenação de toda a logística da cadeia da soja, ampliando os seus limites no sentido "coaseano", pagando os prêmios para os agentes que conseguem fazer a segregação, passando a ser visto com um coordenador de contratos.

PALAVRAS-CHAVE: Contratos; Logística; NEI/ECT; Prêmio.

\section{LOGISTIC AND INSTITUTIONAL ASPECTS AFFECTING SUPPLY OF TRANSGENIC-FREE SOYBEAN}

ABSTRACT: Changes in the Soybean Logistic Chain and its impact to links (producers, stockers/processors, road drivers, train operators and port workers) are identified, owing to the advent and spread of transgenic soybean, under a systemic stance

\footnotetext{
* Administrador de Empresas. Doutor em Transportes (UnB). Faculdade CNEC/Unaí e Centro Universitário do Distrito Federal (UDF). Brasil.

** Doutorado em Ciências Econômicas pelo Universite D'aix Marseille II, Docente do Departamento e Transportes da UnB. Brasil.

*** Doutora em Engenharia de Transportes pela Universidade Federal do Rio de Janeiro (UFRJ). Docente Adjunto III da Universidade de Brasília (UnB). Brasil.

**** Mestrando no Programa de Pós-Graduação em em Agronegócios pela Universidade de Brasília (UnB). Brasil. E-mail: warleyhsilva.eng@gmail.com
} 
of segregation issues. Critical points, care and necessary procedures are identified so that soybean may not been contaminated throughout the chain and the product's purity guaranteed. A segregation prize is thus awarded. Current exploratory and qualitative analysis revealed that the stockers/processors link is crucial within the coordination of the soybean chain logistics, widening its limits, paying prizes to agents that segregate, perceived as coordinators of contracts.

KEY WORDS: Contracts; Logistics; NEI/ECT; Prizes.

\section{INTRODUÇÃO}

A liberação para plantio da soja transgênica no Brasil pela Comissão Técnica Nacional de Biossegurança (CTNBio), em 2005, trouxe implicações para toda a cadeia logística da soja, notadamente no transporte, no manuseio, na limpeza dos veículos e na armazenagem do produto.

A tecnologia dos transgênicos tem sido adotada pelos produtores como forma de buscar melhor desempenho e competitividade. Há evidências em algumas regiões no Brasil de que a adoção da nova tecnologia tem trazido bons resultados econômicos (LEITÃO, 2009; SILVEIRA; BORGES, 2005; SILVEIRA; RESENDE, 2010). Porém, os possíveis ganhos advindos da adoção da tecnologia podem ser dificultados pela necessidade de novas formas de organização dos ativos envolvidos na logística da cadeia da soja, nitidamente no processo do transporte, manuseio e armazenagem do produto. Isso ocorreria principalmente quando há necessidade de segregação entre soja convencional e transgênica.

Importante ressaltar que a mudança trazida pela nova tecnologia dos transgênicos causou transformações na coordenação da cadeia logística da soja como um todo, além de gerar um problema de extrema gravidade, a contaminação da soja convencional pela transgênica. A partir disso, os produtores foram obrigados a ter mais cuidados ao longo de todos os estágios produtivos da soja, já que há fortes indícios de contaminação no desenvolvimento dessas atividades (LEITÃO, 2009; BRAGAGNOLO et al., 2007; CNA, 2008; ESPERANCINI et al., 2008; LEITÃO et al., 2007; MENEGATTI; BARROS, 2007; SILVEIRA; RESENDE, 2010).

Nesse sentido, a segregação é relevante, tendo em vista que existem dois 
mercados, o da soja convencional e o da transgênica. Além disso, devem-se considerar os prêmios pagos aos produtores que produzem soja convencional (LEITÃO, 2009).

Para Silveira e Resende (2010), a segregação é necessária, pois a manipulação de produtos diferenciados em estruturas de armazenamento, as quais estejam voltadas para commodities, é dificultada, o que requer maiores cuidados na recepção, fluxo e limpeza dos silos. Além disso, exige-se mão de obra específica para acompanhar o fluxo do produto diferenciado de menor escala, como no caso da soja convencional.

Outro empecilho que a contaminação pode trazer para os produtores rurais relaciona-se ao pagamento dos royalties, mesmo sem o uso dessa tecnologia. Isso pode ocorrer porque, involuntariamente, a soja pode ser contaminada na compra da semente de soja convencional, caso não haja uma limpeza nas máquinas e equipamentos afins, e nos portos.

Além dos problemas econômicos gerados após o advento da soja transgênica, os produtos geneticamente modificados podem trazer outros problemas de extrema gravidade, notadamente aqueles relacionados à saúde humana. Estudos feitos por Séralini et al. (2007) e Vendomois et al. (2009) mostram o potencial efeito negativo de transgênicos à saúde pública. Esses pesquisadores reavaliaram estatisticamente dados publicados anteriormente pela multinacional Monsanto, e declararam que a alimentação de ratos com milho transgênico, da variedade MON863, provocou toxicidade hepática e renal, bem como alterações no crescimento dos animais.

Corroborando com o que foi relatado anteriormente, Serálini et al. (2012) e Aliaga e Lust (2011) mostram em seus estudos que deve haver um cuidado muito grande na hora de decidir a respeito do consumo de transgênicos, já que eles podem trazer problemas irreversíveis para a saúde animal e, possivelmente, humana.

A American Association of Medical Assistants (AAMA) concluiu que a relação entre os transgênicos e os efeitos negativos na saúde é mais do que uma mera coincidência, e que a ligação causa-efeito é confirmada em vários estudos em animais. Ainda segundo a AAMA (2014), os riscos para a saúde são sérios e incluem a infertilidade, a desregulação imunitária, o envelhecimento acelerado, a desregulação de genes associados à síntese do colesterol, à regulação da insulina, à comunicação 
celular, à síntese proteica e às alterações hepáticas, renais e gastrointestinais.

Além disso, outras pesquisas demonstram que a produção de transgênicos também pode causar efeitos negativos ao meio ambiente. Isso ocorre devido à sua interferência na diversidade e peculiaridades de cada ecossistema. Uma vez introduzida uma planta transgênica, seus efeitos são irreversíveis, pois com a ação dos agentes polinizadores sua propagação é incontrolável (SCHUSTER, 2013).

Segundo Abrange (2014), há uma crescente rejeição aos transgênicos, e existe um aumento da demanda por grãos convencionais. A Europa, assim como a Austrália, a Coréia e o Japão são mercados abertos aos grãos brasileiros que não foram modificados geneticamente. As empresas, no entanto, têm tido dificuldades no processo de segregação entre os grãos transgênicos e convencionais (ABRANGE, 2014).

A preferência para a aquisição de soja livre de transgênicos cai naturalmente sobre o Brasil, país no qual o abastecimento com soja convencional ainda é possível. Frente à perda de mercados, porém, os armazenadores/processadores norte-americanos começam a experimentar sistemas de segregação e oferecem prêmios para grãos convencionais (WILKINSON; PESSANHA, 2005; 2013), fato que também tem acontecido no Brasil (LEITÃO, 2014).

Diante dessas questões, um dos problemas da "nova" cadeia logística da soja passa a ser a contaminação, havendo a necessidade da segregação do produto, pois além dos problemas relacionados ao meio ambiente e à saúde humana, há a possibilidade de recebimento de prêmios para os agentes que conseguem entregar a soja livre de transgênicos. Por outro lado, há a necessidade de investimentos em ativos específicos para que se consiga fazer a separação da soja ao longo da cadeia logística.

A contaminação transgênica tem impacto econômico negativo nos setores da economia que escolhem permanecer livres deste tipo de produto. Como a maioria dos países não tem um sistema de responsabilização pelos organismos geneticamente modificados, os custos para se evitar a contaminação transgênica acabam sendo bancados pelos contaminados, e não pelo contaminador. Esse fenômeno se traduz em uma externalidade negativa, a qual prejudica os agentes e setores que desejam permanecer no modo convencional e orgânico de plantio (FUSCALDI; MEDEIROS; PANTOJA, 2012). Nesse sentido, a atividade de segregação é necessária para 
permitir a convivência dos dois mercados, e tem o custo apontado como empecilho tanto pelos produtores rurais quanto pelos armazenadores/processadores (WILKINSON; PESSANHA, 2005).

Sendo assim, o objetivo deste trabalho foi fazer um mapeamento dos processos críticos da cadeia logística da soja para a não contaminação e a oferta de um produto livre de transgênicos.

\section{ASPECTOS INSTITUCIONAIS QUE INFLUENCIAM A CADEIA LOGÍSTICA DA SOJA}

Toda discussão trazida pela Nova Economia Institucional (NEI) e a Economia dos Custos de Transação (ECT) dão grande suporte para melhor entender a problemática da segregação ao longo da cadeia logística da soja.

Estudar como se dão as transações e os contratos entre os agentes da cadeia logística da soja é essencial para saber qual é a influência destes contratos na estruturação da cadeia, uma vez que eles podem ser formas de incentivo/controle para que os agentes não contaminem a soja ao longo da cadeia e consigam oferecer um produto puro.

Sobre as transações que acontecem entre os agentes dos elos da cadeia logística, é fundamental que haja salvaguardas na presença de ativos específicos, para que não haja quebra de contrato oportunista. Em muitos casos, essas salvaguardas são insuficientes, caindo no pressuposto da racionalidade limitada, a qual impede a elaboração de contratos completos. Esses pressupostos complementares que a teoria neoclássica não abordou são de suma relevância na análise das transações entre os elos da cadeia logística da soja, bem como para saber onde são necessários investimentos em ativos específicos para a segregação, além de ajudar no entendimento do papel que os contratos assumem para mitigar o risco de contaminação ao longo da cadeia logística.

Além dos pressupostos comportamentais (oportunismo e racionalidade limitada), há também atributos inerentes às transações entre os agentes da cadeia logística da soja, as quais se relacionam com os pressupostos comportamentais, como: incerteza, frequência e especificidades dos ativos. 
A incerteza é uma variável do ambiente, e ocorre diante da impossibilidade de se prever com precisão o comportamento dos agentes. Na cadeia logística da soja, a incerteza é patente, porque não se sabe ao certo quando pode haver o pagamento de prêmios, haja vista que não são todos os produtores que dizem receber esse benefício (LEITÃO, 2009; 2014).

A frequência das transações diz respeito à quantidade de vezes que determinada transação é realizada. Com o advento da soja transgênica no mercado brasileiro, as transações entre os agentes da cadeia logística da soja aumentaram consideravelmente. Estudos de Bragagnolo et al. (2007), Leitão (2009), Esperancini et al. (2008), e Fuscaldi, Medeiros e Pantoja (2012) demonstram essa evolução, principalmente pela quantidade de contratos que foram introduzidos para salvaguardar as partes de investimentos em ativos.

Outra característica da transação que deve ser analisada diz respeito à especificidade dos ativos, que é o grau em que determinado ativo pode ser reaproveitado em outra atividade. Logo, quanto menos aproveitável, maior será sua especificidade. A seguir são citadas as especificidades que mais afetam a cadeia logística da soja após o advento dos transgênicos.

a) Especificidade de Ativo Locacional: os ativos envolvidos possuem restrições locacionais, devido às particularidades dos modais utilizados na transação, ou seja, os ativos são imóveis e seu descolamento necessita de elevados custos. No caso da cadeia logística da soja, essa especificidade é relevante, pois caso o produtor consiga fazer a segregação da soja em sua fazenda, e não haja compradores que paguem o prêmio por essa soja em sua região, ele deverá enviá-la para outro local mais distante que faça esse pagamento, aumentando, assim, sua especificidade locacional.

b) Especificidade de Ativo Dedicado: essa especificidade se refere aos aportes de investimentos em ativos, por parte de um agente, com o propósito exclusivo de aumentar a capacidade de oferta, com vistas a atender a quantidade demandada de outro agente. Caso o contrato se interrompa, o agente fornecedor ficará com excesso na capacidade de produção, ou, ao contrário, com uma maior capacidade instalada ociosa. Para a segregação da soja ao longo da cadeia logística, é necessário investimento em alguns ativos dedicados para que se consiga êxito na separação do produto, que serão mostrados na discussão dos resultados. 
c) Especificidade de Ativos Humanos: essa especificidade está relacionada aos investimentos em recursos humanos (qualificação de pessoal), diretamente ou indiretamente comprometidos nas transações. A realização de um processo de aprendizagem contínua torna o capital humano dotado de habilidades específicas.

d) Especificidade mercadológica ou especificidade de marca: está relacionada à construção de um nome, de uma marca, de uma reputação em um determinado mercado (NAVES, 2007). A soja livre de transgênicos é vista pelos mercados que a demandam como de alta qualidade, configurando-se em uma marca a ser zelada, neste caso, em uma especialidade.

Diante do exposto, as transações entre os agentes serão formatadas levando em consideração as características das transações e dos agentes, trabalhadas pela NEI/ECT, sendo estes elementos de fundamental importância para uma melhor análise da problemática sobre a questão da segregação e a oferta de um produto puro, livre de transgênicos.

\section{MATERIAL E MÉTODO}

Inicialmente, foi realizada uma pesquisa exploratória para conhecer com maior profundidade o fenômeno investigado, qual seja a segregação na cadeia logística da soja.

Em seguida, foi realizada uma pesquisa de campo junto aos elos logísticos envolvidos na cadeia da soja. Para a coleta dos dados dessa pesquisa de campo, foram realizadas entrevistas semiestruturadas, que, na visão de Yin (2001), são mais espontâneas e assumem um caráter de conversa informal.

As entrevistas foram feitas com vinte e três especialistas participantes da cadeia logística da soja, sendo doze produtores rurais (dois deles fazem a segregação da soja em suas propriedades, 10 deles deixaram de fazê-la devido à dificuldade operacional e aos altos investimentos necessários em ativos específicos), quatro armazenadores/processadores (um deles faz a segregação em sua unidade, e três deixaram de fazê-la devido à dificuldade operacional e aos altos investimentos necessários em ativos específicos), quatro transportadores rodoviários (que trabalham com o trans- 
porte de soja transgênica e convencional), um operador ferroviário (que trabalha com o transporte de soja transgênica e convencional), e dois operadores portuários (que trabalham com soja transgênica e convencional e fazem a expedição da soja livre de transgênicos para o mercado internacional).

As informações levantadas com os diferentes agentes permitiram mostrar todos os processos da cadeia logística da soja após o advento dos transgênicos, desde a compra da semente até a colocação do produto no porto para exportação.

Todas as entrevistas foram gravadas e realizadas pessoalmente (face a face), segundo orientações de Gil (2010). Quando o critério de representatividade dos grupos investigados é mais qualitativo que quantitativo (como no presente artigo), é recomendável a utilização de amostras selecionadas pelo critério de intencionalidade, pois enriquece ainda mais a pesquisa do tipo qualitativa. Essa forma de amostragem é caracterizada como não probabilística, e foi utilizada no presente trabalho. O Estado de Minas Gerais foi escolhido por apresentar uma produção significativa de soja (5 $5^{\circ}$ maior Estado produtor de grãos do Brasil) (SEAPA, 2014), e por estar distante dos portos de exportação, podendo assim ser mais afetado pelos problemas logísticos, principalmente no transporte e na armazenagem ao longo da cadeia.

Os produtores e armazenadores/processadores de Unaí, Buritis, Arinos e Paracatu foram escolhidos por terem alta representatividade na produção de grãos do Estado de Minas Gerais (SEAPA, 2014).

O restante dos elos pesquisados (transportadores rodoviários e operadores ferroviários e portuários), bem como as regiões da aplicação da pesquisa de campo foi escolhido intencionalmente. A justificativa pela escolha se deu pelo fato dessas regiões estarem situadas no caminho que normalmente a soja do Noroeste faz até chegar ao porto. Para ilustrar a situação, a soja livre de transgênicos que sai de Unaí, por exemplo, tem como destino o armazém de Araguari (MG) (via transporte rodoviário), para ser processada e, posteriormente, enviada (via transporte ferroviário) para o porto de Tubarão (ES) (operador portuário), para expedição ao mercado internacional.

A Figura 1 mostra de forma detalhada as etapas logísticas pelas quais a soja percorre na cadeia, desde a origem na fazenda até seu destino final, no porto. Também destaca onde o produto é armazenado e os modais de transporte utilizados. 


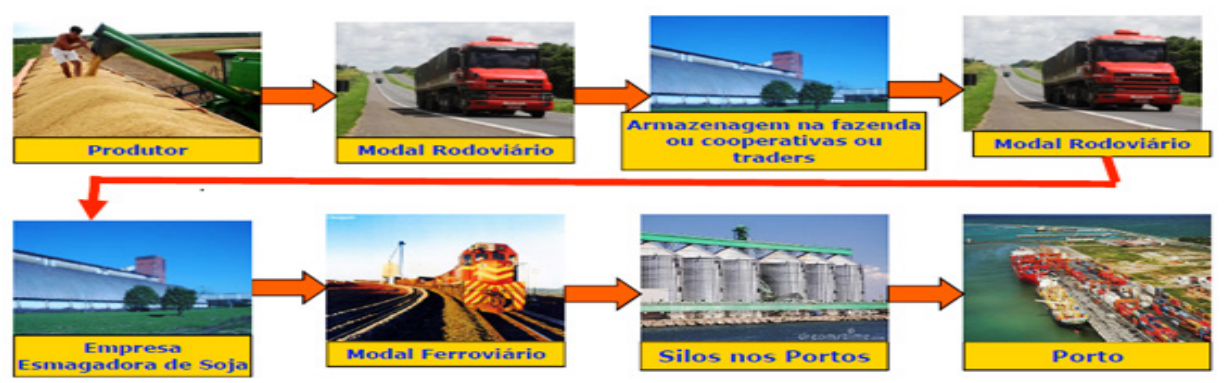

Figura 1. Processo logístico da soja da fazenda do produtor até o porto Fonte: Leitão (2014).

Na Figura 1 pode-se observar que depois da soja ser colhida, o produtor faz o transporte via modo rodoviário até a sede da fazenda (caso tenha armazém), ou envia o produto para uma cooperativa ou trading, a qual fará o armazenamento até que o mesmo seja vendido. Depois de vendida, a soja segue via modo rodoviário até a empresa esmagadora, onde é armazenada e, posteriormente, processada em farelo para exportação. Depois que o farelo de soja é vendido pela esmagadora, segue via modo ferroviário até um armazém perto do porto de Tubarão, local onde é armazenado até sua expedição ao porto. Quando chega ao porto, a soja é armazenada nos porões dos navios para envio ao mercado internacional. Todos os dados foram coletados ao longo do ano de 2014 e serviram de suporte para a discussão dos resultados.

\section{RESULTADOS E DISCUSSÃO}

\subsection{PROCESSO DA COMPRA DE INSUMOS}

Os produtores entrevistados informaram que o problema da contaminação se inicia na compra da semente. Afirmaram que sempre há algum grão transgênico nas sementes de soja que pode contaminar a lavoura da soja convencional. Relataram ainda que as próprias sementeiras reconhecem esse problema. Por isso, eles já estão trabalhando para melhorar seus campos de plantio, deixando-os "mais puros" para mitigar os riscos de contaminação advindos do plantio de grãos contaminados. 
Estudos feitos por Ferment et al. (2009) mostram que pelo menos 9\% das amostras de sementes de soja convencionais testadas apresentam contaminação genética, o que torna ainda mais difícil a segregação e corrobora com o que foi dito pelos produtores entrevistados.

Os produtores informaram ser difícil encontrar sementes de soja convencional com a pureza necessária para fazer o plantio. Para conseguir a semente livre de contaminação, é necessário fazer um planejamento de pelo menos seis meses de antecipação ao plantio para não correr o risco de ficar sem semente com alto teor de pureza perto da entressafra. Caso isso não aconteça, sujeitar-se-ão a comprar semente não garantida de pureza, o que aumentaria drasticamente os riscos de contaminação na lavoura.

Por meio das informações levantadas pode-se perceber a diferença nos cuidados que devem ter ao longo de todo o processo, principalmente os relacionados à limpeza dos caminhões que transportam o adubo do fornecedor até a fazenda. Assim, é possível haver contaminação na descarga da soja na fazenda, uma vez que grãos transgênicos na carroceria, originários de limpeza incorreta, podem sobrar e ser jogados na lavoura da soja convencional. Esses grãos podem germinar, ocasionando a contaminação.

Caso o adubo da soja convencional não seja jogado diretamente na terra em seu transbordo na fazenda, será necessário armazená-lo em local diferente do adubo da transgênica, pois na carga desse adubo não é exigida a limpeza do caminhão, podendo sobrar algum vestígio de grão transgênico na carroceria.

Segundo informações dos produtores, além do cuidado na limpeza dos caminhões, seria necessário ter maior controle no armazenamento do adubo, estocando-o separadamente para minimizar ainda mais os problemas da contaminação.

Um fator contratual importante a ser ressaltado neste processo é a contratação do transportador do adubo. Um dos produtores informou que no momento da contratação há a exigência da limpeza da carroceria, para que o adubo seja transportado, uma vez que o caminhão pode ter feito transporte de soja transgênica e ficado algum vestígio de semente na carroceria. Este adubo, possivelmente, poderá ser jogado na terra, causando a germinação de plantas transgênicas em solos que são destinados à soja convencional, ocasionando, dessa forma, a possível contaminação. 
Atualmente, os produtores exigem do transportador que faz a entrega do adubo na fazenda uma orientação contratual, a fim de que seja feita uma limpeza adequada nos caminhões. Os produtores, no entanto, reconhecem ser difícil fazer a fiscalização para se assegurar que os transportadores realmente cumpram com a exigência da limpeza. A situação ideal seria aquela em que o produtor mandasse um de seus funcionários qualificados para acompanhar a limpeza. Segundo os próprios produtores, a solução para a melhoria desse processo seria que o valor adicional da limpeza fosse solicitado em contrato, para que houvesse maior cuidado nesse processo tão importante para a não contaminação.

Há também a necessidade de armazenamento da semente da soja transgênica de forma separada da soja convencional, de modo que não haja risco de contaminação por algum saco que possa estar danificado, e eventualmente deixe sobras de sementes transgênicas que podem ser varridas e colocadas junto à soja convencional, ou por descuido de algum funcionário que pode pegar o saco por engano.

\subsection{PROCESSO DE PREPARAÇÃO DO SOLO}

A próxima etapa consiste no processo de preparação do solo para o plantio. Neste processo, há maiores cuidados com a soja convencional do que com a transgênica. Para os produtores que fazem a segregação, há processos adicionais que despendem tempos mais longos e maiores custos, conforme será descrito. Nesse sentido, o produtor precisa escolher uma área que tenha menor risco de contaminação para a soja convencional. Logo, áreas nas quais já foi plantada soja transgênica deverão passar por um processo criterioso de limpeza, pois podem ter sobrado grãos remanescentes de soja transgênica que poderão germinar no campo escolhido para a soja convencional. A triagem da área é feita com a ajuda de dados históricos de plantio, sendo escolhidas aquelas áreas onde nunca tenham sido plantada soja transgênica, ou que pelo menos tenha sido utilizado o menor número de vezes possível.

Depois da escolha da área, o próximo passo é fazer as bordas de contenção de 20 metros quadrados para diminuir a possibilidade de contaminação por polinização cruzada. Estudos feitos por Ferment et al. (2009) mostram que esta técnica 
pode reduzir o risco de contaminação a um valor próximo de zero. Isso já é corriqueiramente feito no plantio do milho transgênico, o que está, inclusive, regulamentado por lei. Esses 20 metros, depois de colhidos, são descartados e armazenados juntos à soja transgênica para não correr o risco da contaminação.

\subsection{PROCESSO DE PLANTIO E APLICAÇÃO DOS DEFENSIVOS}

A próxima etapa refere-se ao processo de plantio. O que pode ser constatado é que, no plantio da soja convencional, há mais processos e maiores riscos de contaminação, sobretudo na limpeza das plantadeiras.

Os produtores informaram que para fazer a limpeza é necessário dar manutenção em todas as plantadeiras que fizeram plantação de soja transgênica, tirar toda a soja remanescente, passar uma "vassourinha", assoprar, abrir todas as "caixas" da máquina para que se consiga garantir que não sobrem vestígios de soja transgênica.

O custo aumenta pela necessidade de mais de uma aplicação de defensivos na soja convencional do que na transgênica, uma vez que é necessária apenas uma aplicação na segunda e até quatro na primeira.

Para diminuir o risco de contaminação, faz-se necessário investimento na capacitação e controle dos funcionários que irão fazer o plantio e a colheita, mostrando todos os cuidados e procedimentos que devem ser feitos na limpeza das máquinas, no momento do plantio e da colheita da soja, aumentando a especificidade dos ativos humanos.

\subsection{PROCESSO DE COLHEITA}

Depois que o processo de plantio é realizado, passa-se à colheita. Mais uma vez, pode ser observado que há maior quantidade de atividades no fluxo do processo da soja convencional do que no da transgênica. São elas: limpeza das colheitadeiras, limpeza dos caminhões e espera para o carregamento da soja transgênica (caso as duas estejam sendo carregadas ao mesmo tempo).

Os produtores enfatizaram a necessidade de limpeza muito bem elaborada nas máquinas, para não sobrar nenhum vestígio de grãos transgênicos. Informaram que na oportunidade da colheita chamam todos os funcionários e oferecem um cur- 
so de quase um dia para explicar todos os procedimentos a serem adotados, desde a compra da semente até o momento que a soja sai da fazenda.

Caso o produtor tenha armazém na fazenda, ele armazena a soja e aguarda sua expedição. Se não possui armazém, envia a soja para um armazém terceirizado, ou diretamente para o porto. Se enviar a soja para o armazém terceirizado, deverá estar ciente de que este pode não fazer a segregação em sua unidade, devendo optar pelo envio direto ao porto, caso queira receber os prêmios pela segregação.

\subsection{PROCESSO DE ARMAZENAGEM}

Há duas possibilidades para fazer a armazenagem da soja na própria fazenda: utilizar o mesmo armazém ou unidades totalmente separadas. Primeiramente, será mostrada a estratégia de segregação utilizada por um dos produtores para armazenar a soja em um mesmo armazém. O outro produtor entrevistado faz a segregação em unidades totalmente segregadas. Esse processo será ilustrado posteriormente.

A armazenagem dos dois tipos de soja na mesma instalação é mais complexa, o que gera mais operações para manter a qualidade e pureza do produto. Os processos nos quais se devem ter maiores cuidados para a não contaminação são: orientação e controle dos funcionários para fazer a armazenagem, limpeza da moega, do pátio, dos elevadores, dos secadores e do sugador. Depois que toda a limpeza é realizada, são passadas 200 sacas de soja convencional em todo canal de expedição, a fim de se conseguir a total limpeza. Posteriormente essa soja é descartada como soja transgênica. Por fim, é necessário colocar uma lona de plástico por cima da soja convencional para sua proteção, pois as esteiras carregadas com soja transgênica passam justamente por cima do espaço destinado à soja livre de transgênicos, a qual também é descartada para o armazém da soja transgênica no momento da expedição. Feito isso, pode-se enfim dar início ao processo de armazenagem da soja convencional.

Além disso, antes de a soja ser colocada no armazém, é feito um teste de pureza do produto para saber se todo o processo anterior à armazenagem foi realizado com êxito. Caso seja acusada transgenia, a soja daquele caminhão em que foi feito o teste é descartada e colocada no espaço destinado à soja transgênica. Para 0 total controle e garantia da pureza do produto, é necessário que sejam realizados os testes em todos os caminhões antes de sua entrada no armazém. 
Os produtores informaram que é muito difícil fazer a segregação da soja quando se utiliza o mesmo armazém. Os produtos ficam separados apenas por uma parede de concreto.

Para facilitar o gerenciamento do armazém, os produtores relataram que é importante fazer, primeiramente, toda a colheita de um tipo de soja e posteriormente da outra. Porém, nem sempre se consegue êxito nessa estratégia, porque há diferentes variedades de soja (precoces e tardias), dificultando a gestão do armazém. Quando isso acontece, toda vez que há necessidade de armazenagem da soja convencional, é necessário fazer novamente o processo de limpeza ao longo do armazém.

Nos elevadores e dentro dos silos, é também necessário fazer uma limpeza/ varredura minuciosa para que não reste nenhum grão transgênico. Os produtores informaram que há um risco muito grande de passar soja convencional e transgênica ao mesmo tempo, ainda que elas estejam indo para canais diferentes e em tubulações distintas, porque pode haver algum buraco na tubulação, o qual poderá ocasionar a contaminação. Segundo os produtores, o processo é tão arriscado que mesmo quando os registros das tubulações são fechados, há a possibilidade de contaminação.

Outra forma de fazer a segregação da soja, e evitar maiores problemas de contaminação, é ter um armazém exclusivo para a soja convencional. Um dos produtores entrevistados disse ter um armazém específico só para receber a soja convencional, o que facilita todo o processo. Sendo assim, faz a segregação da soja utilizando unidades de recebimento totalmente segregadas.

Neste caso, as operações de armazenagem para a segregação são drasticamente diminuídas, se comparadas com o processo anterior. Porém, o produtor mencionou que o investimento para a construção de um novo silo específico para o recebimento da soja livre de transgênicos é muito elevado, e só é compensatório se for recebido o prêmio. Sobre este assunto, o produtor argumentou que mesmo fazendo a segregação da soja há anos, não lhe é garantido o recebimento do prêmio. Esse fica nas mãos das tradings (armazenadores/processadores) e o pagamento depende do fechamento de contratos no mercado internacional de entrega da soja livre de transgênicos.

Isso traz uma reflexão sobre a importância dos armazenadores, processado- 
res na cadeia logística da soja, os quais podem ditar comportamentos a montante e a jusante, pois são eles que coordenam todos os contratos de compra e venda da soja livre de transgênicos, além de fazerem o pagamento do prêmio para os produtores a partir do fechamento de contratos no mercado internacional.

Diante dessa informação, pode-se afirmar que os armazenadores são vistos como coordenadores de contratos, em que a confecção destes com cada elo da cadeia merecerá tratamento diferente.

Com relação aos contratos, ressalta-se que sua elaboração e acordo entre armazenador/processador (que paga o prêmio) e produtor rural (que recebe o prêmio) dependerá da quantidade de produtores ofertantes capazes de entregar a soja livre de transgênicos (quanto mais ofertantes, menor será o preço do prêmio pago ao produtor; lei da oferta e demanda), e de sua reputação, baseada no histórico de fornecimento da soja não contaminada (pois há histórico de produtores que fecharam contratos de entrega de soja livre de transgênicos, porém não conseguiram honrar seus compromissos, entregando soja contaminada).

O Quadro 1 traz um resumo da percepção dos armazenadores/processadores quanto às principais mudanças que a cadeia logística da soja sofreu após o advento e a difusão dos transgênicos.

Quadro 1. Principais mudanças na cadeia logística da soja sob a ótica do armazenador/ processador

\begin{tabular}{|l|l|}
\hline Prêmios & $\begin{array}{l}\text { 1-Recebe prêmios do mercado internacional; 2-Paga prêmios para os produ- } \\
\text { tores e operadores portuários; 3-Não paga prêmios para os transportadores ro- } \\
\text { doviários e ferroviários; 4-Se acusado 1 grão em 1.000 no teste de transgenia, } \\
\text { não há pagamento de prêmio e pode executar o contrato. }\end{array}$ \\
\hline $\begin{array}{l}\text { Riscos de Con- } \\
\text { taminação }\end{array}$ & 1-Semente; 2-Transporte; 3-Armazenagem; 4-Transbordo. \\
\hline $\begin{array}{l}\text { Estratégias de } \\
\text { Segregação }\end{array}$ & $\begin{array}{l}\text { 1-Ter duas unidades receptoras, uma para cada tipo de soja; 2-Limpeza minuci- } \\
\text { osa em todas as máquinas e equipamentos no armazém; 3-Cursos de capac- } \\
\text { itação para todos os funcionários; 4-Cobrar dos transportadores rodoviários } \\
\text { e ferroviários a limpeza minuciosa dos seus caminhões e vagões, porém, não } \\
\text { paga prêmio nem frete diferenciado. }\end{array}$ \\
\hline Contratos & $\begin{array}{l}\text { 1-Faz contratos com a Monsanto para recolhimento de royalties; 2-Faz contra- } \\
\text { to de venda com os países importadores; 3-Faz contrato com os produtores; } \\
\text { 4-Faz contrato com um armazém próximo ao porto; 5-Faz contratos com os } \\
\text { operadores portuários. }\end{array}$ \\
\hline
\end{tabular}

Fonte: Elaborado pelos autores (2014). 
O Quadro 2 traz um resumo das principais dificuldades para fazer a segregação, onde acreditam ter maior possibilidade de contaminação, e quais estratégias podem ser utilizadas para se fazer a segregação.

Quadro 2. Armazenadores/processadores que não fazem a segregação da soja

\begin{tabular}{|l|l|}
\hline $\begin{array}{l}\text { Dificuldades para } \\
\text { fazer a segregação }\end{array}$ & $\begin{array}{l}\text { 1-É demorado fazer os testes de transgenia; 2-Dificuldade na estocagem } \\
\text { das duas sojas; 3-Custos com a construção de um novo armazém; 4-Di- } \\
\text { ficuldade no gerenciamento dos armazéns; 5-Ociosidade dos armazéns; } \\
\text { 6-Aumento dos custos de recepção, secagem e armazenagem; 7-Não } \\
\text { garantia de recebimento de prêmios pela segregação do produto. }\end{array}$ \\
\hline $\begin{array}{l}\text { Onde acreditam ter } \\
\text { maior possibilidade } \\
\text { de contaminação }\end{array}$ & $\begin{array}{l}\text { 1-Plantio; 2-Colheita; 3-Transporte; 4-Semente; 5-Armazenagem; 6-Trans- } \\
\text { bordo. }\end{array}$ \\
\hline $\begin{array}{l}\text { Estratégias para se } \\
\text { fazer a segregação }\end{array}$ & $\begin{array}{l}\text { 1-Maquinários e equipamentos destinados exclusivamente para manuseio } \\
\text { da soja convencional, como secadores, moegas e silos, ou utilizar os } \\
\text { mesmos nos dois processos, porém passando por um procedimento de } \\
\text { limpeza rigoroso; 2-Construção de um novo armazém exclusivo para o } \\
\text { recebimento de soja convencional; 3-Fazer contrato com os produtores } \\
\text { para recebimento de soja GMO FREE; 4-Necessidade de cursos de capaci- } \\
\text { tação para os funcionários. }\end{array}$ \\
\hline
\end{tabular}

Fonte: Elaborado pelos autores (2014).

\subsection{PROCESSO DE VENDA/EXPEDIÇÃO DA SOJA ATÉ O PORTO UTILIZANDO O MODAL RODOVIÁRIO}

O processo da soja convencional é mais demorado do que da soja transgênica, uma vez que há necessidade de fazer a limpeza em todo o canal de expedição quando a soja é vendida, como a retirada da lona e o descarte da soja remanescente no armazém da soja transgênica. Importante ressaltar a relevância da limpeza das esteiras que irão fazer o transbordo do armazém para o caminhão. Novamente, é necessário que se faça o carregamento da soja convencional, em primeiro lugar, para reduzir os riscos de contaminação. Caso a soja transgênica seja carregada primeiro será necessário esperar o término de todo o processo para dar início ao processo da soja convencional, para não correr riscos de contaminação.

Geralmente, os produtores das cidades de Unaí (MG), Arinos (MG) e Paracatu $(\mathrm{MG})$ enviam a soja segregada de sua fazenda até uma empresa armazenadora/ 
processadora que se encontra na cidade de Araguari $(\mathrm{MG})$, via modal rodoviário. Depois que a soja é recebida e processada pela armazenadora/processadora, é utilizado o modal ferroviário para envio da soja até o porto para exportação. No entanto, há produtores que segregam a soja e a enviam diretamente para o porto, utilizando, para isso, apenas o modal rodoviário, sem passar por empresa armazenadora/processadora ou utilizar outro modal de transporte.

\subsection{PROCESSO DE VENDA/EXPEDIÇÃO DA SOJA ATÉ O PORTO UTILIZANDO O MODAL FERROVIÁRIO}

Quando utilizado o modal ferroviário, faz-se necessária a limpeza em todas as máquinas e equipamentos para a expedição da soja livre de transgênicos do armazenador/processador. Com este processo finalizado, a empresa deve contratar um terceiro para a emissão do laudo sobre a carga, atestando a pureza do produto. Se acusar contaminação, a empresa não carrega a soja, ou envia a carga para outro porto que não faz a segregação da soja.

Em caso de não contaminação, a empresa contrata o serviço do terminal ferroviário, cobra a limpeza minuciosa dos vagões, e faz limpeza minuciosa das esteiras que farão o transbordo da soja do armazém para o trem. Importante ressaltar que se os dois tipos de soja estiverem sendo carregados em vagões distintos próximos uns ao outro, é necessário esperar o carregamento da soja transgênica para não correr o risco de contaminação. Finalizado o carregamento do trem, a soja é transportada até o armazém no porto que faz a segregação da soja.

\subsection{PROCESSO DE ARMAZENAGEM DO TREM OU CAMINHÃO NO PORTO}

Quando a soja chega ao armazém no porto para exportação, novamente, contrata-se uma empresa terceirizada para emitir o laudo sobre a carga, atestando a qualidade do produto. Caso seja acusada transgenia, a soja é enviada para o espaço destinado ao armazenamento dos transgênicos e aguardará expedição para o navio. Importante ressaltar que em caso de contaminação não haverá pagamento de prêmios para o dono da carga. 
Caso não seja acusada a transgenia, é necessário fazer uma limpeza minuciosa nas esteiras que farão o transbordo do caminhão ou do trem para o espaço destinado ao armazenamento da soja convencional. Depois que é feito este processo, a soja é armazenada e aguardará expedição para o navio.

\subsection{PROCESSO DE EXPEDIÇÃO DA SOJA DO ARMAZÉM NO PORTO PARA O NAVIO}

Neste processo, é necessário um terceiro emitir, novamente, o laudo sobre a pureza do produto. Caso haja contaminação, a soja é enviada para o porão destinado à armazenagem da soja transgênica. Caso contrário, é preciso fazer a limpeza minuciosa do porão que irá receber a soja convencional, e também das esteiras que farão o transporte do armazém para o navio. Feito isso, a soja poderá ser armazenada para ser enviada ao mercado internacional.

Todos os processos da cadeia logística da soja foram desvendados, desde o momento da compra dos insumos até o momento da expedição dos produtos no navio para exportação, mostrando que, realmente, na cadeia logística da soja convencional, deve haver maiores cuidados, em se comparando com a cadeia da soja transgênica, trazendo aumento nos custos pela necessidade da segregação.

\section{CONSIDERAÇÕES FINAIS}

Uma análise sistêmica da cadeia logística da soja permitiu identificar os gargalos existentes, principalmente no que tange à segregação e aos riscos de contaminação após o advento e a difusão da soja transgênica no Brasil. Com isso, foi possível identificar as etapas logísticas com maior possilidade de contaminação, e propor, por conseguinte, formas de se fazer a segregação, desde a compra da semente até a colocação do produto no navio para exportação.

Importante ressaltar que o presente trabalho permitiu identificar a estrutura atual da cadeia logística da soja, mostrando todos os procedimentos necessários ao processo de segregação sem contaminação. Sendo assim, hoje, são conhecidos os processos da cadeia logística em que há maior possibilidade de contaminação. 
Além disso, foi identificado o que precisa ser feito para a não contaminação da soja convencional. Com essas informações, os agentes que atualmente não fazem a segregação terão maior racionalidade para tomar sua decisão na tomada de decisão em aderir ou não à separação da soja.

Nesse sentido, a necessária atividade de segregação, para permitir a oferta da soja livre de transgênicos, tem o seu custo apontado como empecilho para os agentes da cadeia. Contudo, parece estar delineado que se continuar havendo o pagamento do prêmio, estes agentes terão incentivos para continuar com a segregação da soja. O referido custo diz respeito não apenas às modificações técnicas nas fases de produção, transporte e armazenamento, mas também aos custos de transação em que incorrem os agentes envolvidos nessa cadeia, principalmente os custos relacionados aos tempos necessários para fazer cada operação adicional necessária à segregação e aos custos para a gestão dos contratos.

Contudo, para os "novos entrantes", o investimento em ativos humanos e físicos pode desestimular a segregação, pois os custos de saída são elevados, capitaneados principalmente pelas incertezas inerentes ao pagamento do prêmio.

Vale ressaltar a influência dos armazenadores/processadores nessa cadeia, utilizando de diversas estratégias para conseguirem a segregação internamente, e ao longo da cadeia. Eles podem ser vistos como o coordenador dos contratos dessa cadeia, ampliando seus limites no sentido "coaseano", amarrando contratos com todos os elos da cadeia logística para a garantia da entrega do produto livre de transgênicos aos mercados que a demandam, ditando o comportamento da cadeia.

Seria relevante que as informações apresentadas fossem mais bem disseminadas com todos os agentes, pois alguns deles que estão ganhando valores mais elevados, como os armazenadores/processadores, parecem não ter interesse em divulgar essas informações para o restante da cadeia. Isso aumenta os custos de transação ao longo da cadeia, através da racionalidade limitada dos outros agentes pela assimetria de informação que o armazenador/processador tem sobre os demais, configurando-se em oportunismo, pois utilizam de informações privilegiadas para levar vantagem em suas transações, principalmente sobre os transportadores rodoviários e ferroviários que não recebem o prêmio devido pela segregação da soja.

Mais uma vez, o poder de fazer valer seus interesses, parece estar com os 
elos mais fortes da cadeia, neste caso o armazenador/processador, que ditará as "regras do jogo" caso a informação não seja disseminada de forma simétrica para todos os agentes. Está claro que os elos mais fracos da cadeia (produtores, transportadores rodoviários e ferroviários) acabam assumindo o ônus da segregação para que os mais fortes (armazenadores/processadores) possam tirar proveito dos ganhos advindos da não contaminação da soja.

Devido à importância do papel dos contratos nos deslindes dos aspectos subjetivos cercados de sigilo e variáveis intangíveis, como o oportunismo, racionalidade dos agentes e a incerteza, seria interessante o desenvolvimento em parceria com estudiosos da ciência da informação, notadamente na área de inteligência artificial para mitigar esses impactos. Para tanto, dentro da etapa de suporte da cadeia logística da soja, chamada de manutenção da informação, seria interessante desenvolver agentes inteligentes capazes de classificar níveis de incertezas na tomada de decisão, em função da ambiguidade das informações e do oportunismo.

\section{REFERÊNCIAS}

AAMA - American Academy of Environmental Medicine. The American Academy Of Environmental Medicine Calls For Immediate Moratorium On Genetically Modified Foods. Disponível em: < http://www.stopogm.net/sites/stopogm.net/files/ AAMApressrel.pdf>. Acesso em: 24 jun. 2014.

ABRANGE - Associação Brasileira de Produtores de Grãos não Geneticamente Modificados. Disponível em: < http://planetaorganico.com.br/site/index.php/gmo-free-livre-de-transgenicos/> Acesso em: 20 jun. 2014.

ALIAGA, F.; LUST, C. Violations of human rights as a result of GM soy. GMOs in agriculture again a theme on UN-committee of human rights. Geneva, 2011.

BRAGAGNOLO, C.; MAFIOLETTI, R. L.; SBRISSIA, G. F.; TURRA, F. E. Análise dos custos de produção da soja no Paraná: Convencional X Transgênica (RR). In: CONGRESSO BRASILEIRO DE ECONOMIA E SOCIOLOGIA RURAL SOBER., 43., Anais.... Londrina-PR: 2007. CD-ROM.

CNA - Confederação da Agricultura e Pecuária do Brasil. Boletim Ativos de Grãos. 
Superintendência técnica da CNA - Confederação da Agricultura e Pecuária do Brasil e Centro de Estudos Avançados em Economia Aplicada - Cepea/Esalq. Dados Internos Ano 2, edição 2, 2008.

ESPERANCINI, M. S. T.; FURLANETO, F. P. B.; RECO, P. C.; OJIMA, A. L. R. O.; YASUDA, G. M. Retorno e risco econômico no cultivo de soja convencional e transgênica na região paulista do médio Paranapanema, safra 2006/7. In: CONGRESSO BRASILEIRO DE ECONOMIA E SOCIOLOGIA RURAL SOBER, 43., Anais... Rio Branco, AC, 2008. CD-ROM.

FERMENT, G.; ZANONI, M.; BRACK, P.; KAGEYAMA, P.; NODARI, R. O. Coexistência, o caso do milho. Proposta de Revisão da Resolução Normativa no 4 da CTNBIo. MDA, Brasília, 2009. Disponível em: < http://www.bs.cca.ufsc.br/publicacoes/coexistenciamilho.pdf\# page $=1 \&$ zoom $=$ auto,639,847> Acesso em: 02 out. 2013.

FUSCALDI, K.; MEDEIROS, J. X.; PANTOJA, M. J. Soja Convencional e Transgênica: percepção de atores do SAG da soja sobre esta coexistência. RESR, Piracicaba, SP, v. 49, n. 04, p. 991-1020, out/dez 2011.

GIL, A. C. Como elaborar projetos de Pesquisa. 5. ed. São Paulo: Atlas, 2010. 184 p.

HEINEMANN, J. A. Report on animals exposed to GM ingredients in animal feed. Prepared for th Commerce Commission of Ney Zealand, 2009.

LEITÃO, F. O.; MEDEIROS, J. X.; RIBEIRO, J. G. B. L.; FOK, M.; VILLAR, P. M. del. Análise da Percepção dos Armazenadores Processadores de Soja Sobre a Dinâmica da Soja GM e NGM. Artigo apresentado no seminário GICOGM. Brasília, 2007.

LEITÃO, F. O. Análise da coexistência da soja transgênica e convencional em Mato Grosso: rumo a novas formas de governança. Dissertação (Mestrado em Agronegócios) - UNB, Brasília, 2009.

LEITÃO, F. O. Análise Sistêmica da Segregação na Cadeia Logística da Soja após o Advento e a Difusão dos Transgênicos. Tese (Doutorado em Transportes) - UNB, Brasília, 2014.

MENEGATTI, A. L. A.; BARROS, A. L. M. Análise comparativa dos custos de produção entre soja transgênica e convencional: um estudo de caso para o Estado do Mato 
Grosso do Sul. Revista de Economia Rural, v. 45, p. 163-183. Rio de Janeiro, 2007.

NAVES, I. M. Agronegócio e logística: dicotomia. In: CONGRESSO DA SOBER, 45. Anais... Londrina: Sociedade Brasileira de Economia, Administração e Sociologia Rural, 2007.

SCHUSTER, I. Fluxo gênico e coexistência de lavouras com espécies transgênicas e convencionais. Informativo ABRATES, v. 23, n. 1, 2013.

SEAPA - Secretaria de Estado de Agricultura, Pecuária e Abastecimento. Estatísticas do Estado de Minas Gerais. Disponível em: < http://www.agricultura.mg.gov. br/ $>$. Acesso em: 20 jun. 2014.

SÉRALINI, G. E.; CELLIER, D.; VENDOMOIS, J. S. New analysis of a rat feeding study with a genetically modified maize reveals signs of hepatorenal toxicity. Archives of environmental contamination and toxicology, 2007.

SILVEIRA, J. M. F. J.; BORGES, I. C. Impactos Socioeconômicos da Difusão de OGM no Brasil. In: INTERNATIONAL PENSA CONFERENCE ON AGRIFOOD CHAINS/NETWORKS ECONOMICS AND MANAGEMENT, 5., Anais... Ribeirão Preto: 2005. CD-ROM.

SILVEIRA, J. V. F.; RESENDE, L. M. Estratégias de mercado no agronegócio paranaense: soja convencional vs. transgênica. Produção, v. 20, n. 1, jan./mar. 2010, p. 54-65.

VENDOMOIS, J. S.; ROULIER, F.; CELLIER, D.; SÉRALINI, G. E. A Comparison of the Effects of Three GM Corn Varieties on Mammalian. International Journal of Biological Sciences, v. 5, n. 7, p. 706-726, 2009.

WILKINSON, J.; PESSANHA, L. Transgênicos e a Competitividade Brasileira Face aos Desafios de Novas Formas de Coordenação nas Cadeias de Grãos. In: CONGRESSO BRASILEIRO DE ECONOMIA E SOCIOLOGIA RURAL SOBER, 43., Anais... Ribeirão Preto, 2005. CD-ROM.

WILKINSON, J.; PESSANHA, L. A Institucionalização Do Conflito Em Torno Da Biossegurança Dos Transgênicos na Agricultura: os casos do Brasil e Argentina. In: ENCONTRO NACIONAL DA ANPPAS, 4., Anais... 2008. Brasília. Disponível em: < http:// www.anppas.org.br/encontro4/cd/ARQUIVOS/GT140913920080506133746.p>. Acesso em: 27 fev. 2013. 
YIN, R. K. Estudo de caso: planejamento e métodos. 2. ed. Porto Alegre: Bookman, 2001. $205 \mathrm{p}$.

Recebido em: 04/04/2016 Aceito em: 05/11/2017 